\title{
Psicodiagnóstico e Psicoterapia Dimensões e Paradoxos
}

\author{
Psychodiagnostic and psychoterapy \\ dimensions and paradoxes
}

Ari Pedro Balieiro Junior

Universidade de Franca

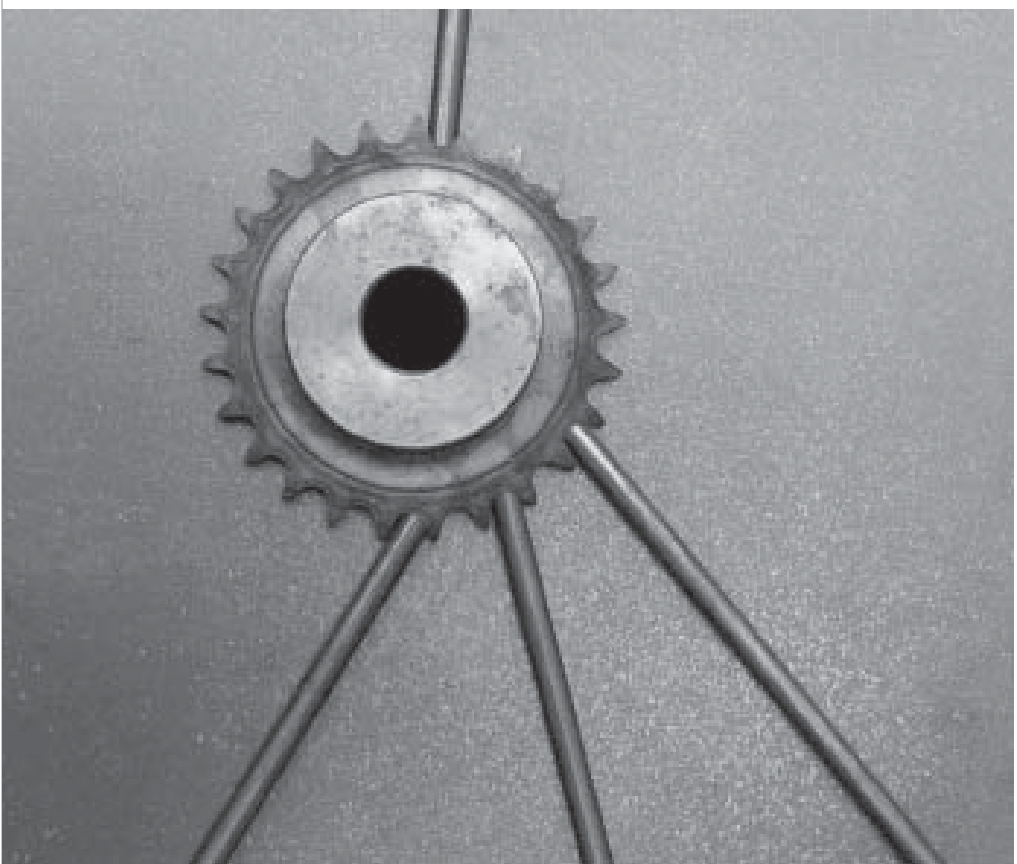




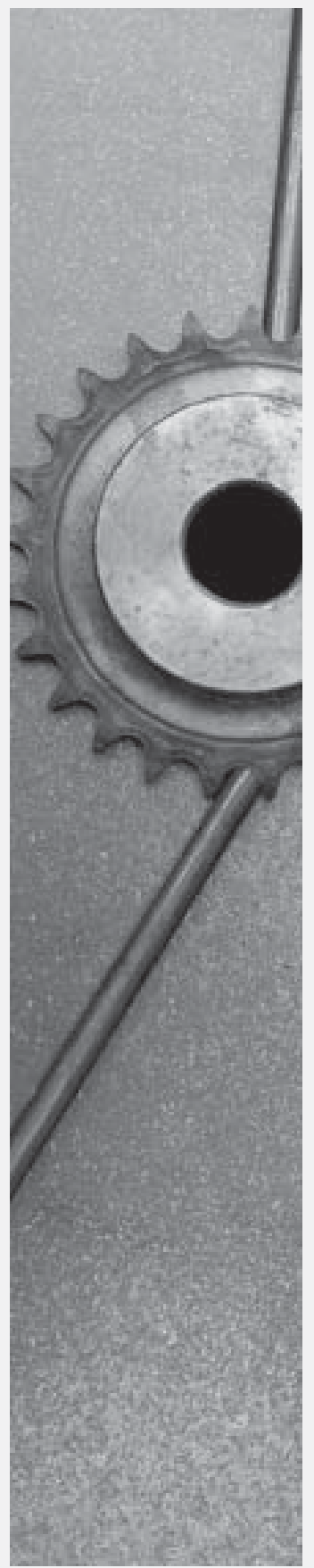

Resumo:Este ensaio examina as relações entre psicodiagnóstico e psicoterapia, pressupondo que a prática da psicoterapia implica duas dimensões não coincidentes. Por um lado, é uma prática social reconhecida e regulamentada, uma dimensão pública. Por outro lado, é um certo tipo de relação entre pessoas, uma dimensão privada. O ensaio começa abordando a relação entre a prática do psicodiagnóstico e o debate teórico - sobre a doença mental e seu tratamento - que tem dominado o panorama da Psicologia e da psiquiatria no século XX. Em seguida, apresenta rapidamente a teoria dos tipos lógicos, assentando as bases das análises que se seguirão. Então, examina a prática psicodiagnóstica e psicoterápica em busca de problemas causados pela tensão entre as determinações impostas por aquelas duas dimensões. Finalmente, argumenta por um debate coletivo que permita a construção e o progressivo aperfeiçoamento dos parâmetros que devem balizar a prática do psicodiagnóstico e da psicoterapia.

Palavras-chave: psicodiagnóstico, psicoterapia, epistemologia, prática profissional.

Abstract: This paper inquires the relations between psychodiagnostic and psychotherapy, assuming that the practice of psychotherapy implies two dimensions witch are not coincident. On one hand, it is a regulated and recognized social practice, a public dimension. On the other hand, it is a certain kind of relationship between persons, a private dimension. The paper begins broaching the relationship between the practice of psychodiagnostic and the theoretic debate - about mental illness and its treatments - which have been dominant in the landscape of Psychology and psychiatry in the $\mathrm{XX}^{\text {th }}$ century. After that, it introduces the logic type theory to establish the basis of the following analysis. Then, it examines the practice of psychodiagnostics and psychotherapy, looking for the problems that can be caused by the tension between the determinations imposed by those two dimensions. Finally, it argues by a collective debate that allows the construction and the progressive improvement of the parameters that must be considered in the practice of psychodiagnostics and psychoterapy.

Key words: psychodiagnostic, psychotherapy, epistemology, professional practice.
"Acredito, também, que virá o dia em que, sofrendo sem saber por que, nos entregaremos a uns físicos que, sem sequer nos interrogar, nos tirarão uma amostra de sangue da qual deduzirão algumas constantes a serem logo multiplicadas umas pelas outras. Depois do que, consultando uma tábua de logaritmos, nos curarão com uma pílula. E, no entanto, quando eu sofrer, irei provisoriamente a um velho médico do interior, que me observará do canto do olho, baterá na minha barriga, colará contra meus ombros um velho lenço, através do qual escutará. Depois, tossirá um pouco, acenderá o cachimbo, esfregará o queixo e me sorrirá para melhor me curar."

Antoine de SaintExupéry (1984, p. 27). 
Nas palavras de Jurema Alcides Cunha: "O psicodiagnóstico é uma tarefa do psicólogo clínico e a única que lhe é privativa. É pois, de fundamental importância que consiga exercê-la bem" (2000b, p. IX). Embora possa ser praticado com vários objetivos (Cunha, 2000d), a relação mais evidente do psicodiagnóstico é com a psicoterapia.

O prestígio da atividade psicodiagnóstica e sua conseqüente relação com a atividade psicoterapêutica, entretanto, tem variado ao longo do tempo, em um leque que abrange

psicodiagnóstico é uma tarefa do psicólogo clínico e a única que lhe é privativa. É pois, de fundamental importância que consiga exercê-la bem"

Jurema Alcides Cunha: desde posições em que o psicodiagnóstico é considerado como a primeira e indispensável etapa da psicoterapia até posições que o consideram "inútil", "desumanizante" ou "autoritário". Também sua prática, e as técnicas nela envolvidas, tem variado ao longo do tempo, ora privilegiando instrumentos de medida, como testes e escalas, ora privilegiando o papel do investigador, como nas entrevistas clínicas.

Nesta reflexão, proponho-me a examinar as atividades de psicodiagnóstico, e suas relações com a psicoterapia de um ponto de vista que pressupõe que a prática da psicoterapia implica e é determinada por condições oriundas de duas dimensões não completamente coincidentes. Por um lado, é um serviço profissional prestado por uma pessoa ocupando o papel de terapeuta a uma (ou mais de uma) pessoa ocupando o papel de cliente, ou seja, uma prática social reconhecida e regulamentada, o que configura uma dimensão pública com particularidades e determinações específicas oriundas das condições sociohistórico-políticas em que essa prestação de serviço ocorre. Por outro lado, o fundamento desse serviço é o estabelecimento de um certo tipo de relação entre as pessoas que ocupam aqueles papéis, o que configura uma dimensão privada com particularidades e determinações de ordem interpessoal e intrapessoal, ou individual. Sustento que o entrecruzamento das determinações impostas por essas duas dimensões é um fenômeno complexo e nãolinear que gera vários tipos de problemas e paradoxos, cuja consideração é crucial para o aperfeiçoamento da prática profissional tanto em psicodiagnóstico quanto em psicoterapia. Começarei este ensaio com uma pequena digressão histórica sobre a relação entre a prática do psicodiagnóstico e o debate teórico - sobre a doença mental e seu tratamento que tem dominado o panorama da Psicologia e da psiquiatria no século XX. Em seguida, apresentarei rapidamente a teoria dos tipos lógicos para assentar as bases das análises que virão a seguir. Então, empreenderei um exame da prática psicodiagnóstica e psicoterápica em busca dos problemas que podem ser causados pela tensão entre as determinações não coincidentes ou paradoxais impostas por aquelas duas dimensões. Finalmente, à guisa de conclusão, alinharei argumentos a favor de um debate que só pode ser frutífero como um empreendimento coletivo que permita a construção e o progressivo aperfeiçoamento dos parâmetros que devem balizar a prática do psicodiagnóstico e da psicoterapia.

Uma última observação: procurei manter este debate o mais isento possível de filiação a uma escola ou doutrina psicológica, mas gostaria de deixar claro minha própria posição, tanto para ser coerente com a idéia de empreendimento coletivo que advogo quanto para permitir que os vieses que não logrei eliminar sejam visíveis àqueles que abordam o problema a partir de outros lugares teóricos. Meu primeiro contato com a Psicologia foi através de uma leitura adolescente da obra de Sigmund Freud, de quem sempre admirei, e ainda admiro, o arguto poder de observação e a ousadia para explorar caminhos teóricos inusitados. Iniciei minha prática de psicoterapia há dezesseis anos, a partir de um posicionamento inspirado em Carl Rogers, que conheci ainda na escola. Em um nível teórico, meu contato com Piaget foi uma revelação, tanto pela profundidade dos insights quanto 
pela solidez do quadro teórico que aparece em suas obras. Num nível mais abstrato, como cientista, minha imensa admiração pelo profundo rigor epistemológico de Skinner manteve-me sempre insatisfeito com a qualidade das explicações apresentadas pelas várias escolas. Essa insatisfação levou-me a explorar várias linhas explicativas, até que encontrei, via Gregory Bateson, a cibernética e a teoria de sistemas. Hoje, diria que sou um psicoterapeuta cognitivo-comportamental com um forte acento construtivista, na linha que é bem exemplificada por Michael J. Mahoney e, no Brasil, pelas publicações de Cristiano Nabuco de Abreu.

\section{Um pouco de história}

“Psicodiagnóstico é uma avaliação psicológica feita com propósitos clínicos; portanto, não abarca todos os modelos de avaliação psicológica de diferenças individuais" (Cunha, 2000c, p. 19) Em outras palavras, o psicodiagnóstico é um tipo de avaliação psicológica estreitamente vinculado à prática clínica em saúde mental. Assim, durante o século XX, o prestígio do psicodiagnóstico e a prática concreta das estratégias de avaliação psicodiagnósticas refletiram o debate teórico, que vem marcando o campo da saúde mental desde seus primórdios, entre as "principais correntes de pensamento que salientaram, cada uma, a primazia do comportamento, do afeto e da cognição na organização e no funcionamento do psiquismo humano" (idem, ibidem).

Em uma de suas vertentes, aquela mais diretamente ligada ao psicodiagnóstico, o debate levou a comunidade científica à percepção de que era necessário algum tipo de padronização que criasse um campo comum às diferentes correntes de pensamento, estabelecendo bases para um debate frutífero. A idéia de um sistema de classificação diagnóstica unificada foi conseqüência do desenvolvimento, no século XIX, dos serviços de saúde pública e sua necessidade de estatísticas confiáveis (OMS, 1993; APA, 1995; Lopes, 1997). Na área específica da saúde mental, no entanto, a primeira iniciativa internacional consolidada surgiu em 1948, como uma seção da sexta edição da Classificação Internacional de Doenças (CID-6), publicada pela Organização Mundial da Saúde. Em 1952, a Associação Psiquiátrica Americana (APA) publicou a primeira edição de seu Manual Diagnóstico e Estatístico de Transtornos Mentais (DSM-I). A partir daí, e sucessivamente, o sistema de diagnóstico e classificação tem evoluído através de várias revisões e aperfeiçoamentos que, se ainda não mostram uma clara convergência em direção à pretendida base comum, já são um evidente fruto do debate e do diálogo entre os principais grupos de pesquisadores da área. Atualmente, o sistema se manifesta na publicação do CID-10 (OMS, 1993) e do DSM-IV (APA, 1995). A característica mais típica desse sistema, em seu atual estágio, é uma metodologia descritiva fortemente baseada em evidências empíricas que busca a neutralidade em relação às teorias etiológicas sobre as doenças, em boa parte herança da tradição médica, ou, mais especificamente, da fenomenologia psiquiátrica. ${ }^{1}$

Na outra vertente, mais diretamente ligada às práticas psicoterápicas, o debate provocou o surgimento de um grande número de "escolas" psicoterápicas que se alternaram em visibilidade e prestígio. De maneira geral, o século XX assistiu a um acirrado debate entre as chamadas "três forças" - a(s) psicanálise(s), $\mathrm{o}(\mathrm{s})$ behaviorismo(s) e o(s) humanismo(s) que, embora começando timidamente, alcançou altíssimas temperaturas (com claras tinturas ideológicas) nas décadas de 60 e 70 e promoveu um grande desenvolvimento da área, discutindo questões relativas à teoria psicológica e psicopatológica, especialmente no campo da teoria da personalidade e das teorias sobre o estatuto e a etiologia da "doença
De maneira geral, o século XX assistiu a um acirrado debate entre as chamadas "três forças" - a(s) psicanálise(s), o(s) behaviorismo(s) e o(s) humanismo(s) que, embora começando timidamente, alcançou altíssimas temperaturas (com claras tinturas ideológicas) nas décadas de 60 e 70 e promoveu um grande desenvolvimento da área,
1 Este projeto de "busca de neutralidade" não é isento de problemas, críticas ou paradoxos, tanto em termos puramente epistemológicos quanto em termos doutrinários. Veja-se, por exemplo, Silva Junior e Ferraz (2001). Ainda assim é forcoso reconhecer que, mesmo para acueles que contribuem para aqueles que contribuem para 0 sistema, ou o adotam, essa neutralidade é considerada provisória, uma etapa necessária de um projeto mais amplo. 
mental", e questões relativas à teoria e prática da psicoterapia, especialmente quanto à eficácia, alcance e aplicabilidade dos vários modelos teóricos, e quanto à própria natureza da relação psicoterápica. Assim como na outra vertente, o final do século XX tem assistido a um crescente diálogo entre as diferentes correntes, que, se não garante que venha a ser produzido um paradigma unificado, tem, inegavelmente, produzido algum tipo de convergência entre os paradigmas. ${ }^{2}$

\section{A questão dos tipos lógicos}

Whitehead e Russel (1910) propuseram a teoria dos tipos lógicos como uma tautologia que permite esclarecer a geração dos paradoxos do gênero "Epimênides de Creta", ou paradoxos russelianos. Parafraseando seu axioma central, podemos dizer que "o que quer que envolva a totalidade de uma coleção não pode fazer parte dessa coleção". ${ }^{3}$ Assim, eventos, indivíduos, declarações ou proposições, bem como nomes, etc., organizam-se em conjuntos que podem ser distribuídos em níveis, ou tipos lógicos, em que eventos ou indivíduos são agrupados em conjuntos ou classes, que, por sua vez, são agrupados em conjuntos de conjuntos, ou classes de classes, e assim por diante. Os paradoxos são gerados toda vez que declarações referentes a um determinado nível são operadas com declarações referentes a outro nível, e tratadas como logicamente equivalentes.

2 Essa convergência também não é isenta de problemas, críticas $e$ paradoxos. Como um exemplo de posiçóes opostas sobre essa questio, podemos citar Beck e Alford (2000), que argumentam pela possibilidade dessa convergência, e Figueiredo (1991), que argumenta que essa convergência não é possivel, ou, mesmo, desejável. Para uma posição com a qual me identifico, ver Mahoney (1998).

3 Whitehead, A. N., e Russel, B., Principia Russel, B., Principia
Mathematicar (apud Watzlawick 1977, p. 23). verdadeira... e recomeça o circuito. Russel e Whitehead demonstraram que o paradoxo é gerado porque a asserção é um conjunto que contém outro conjunto (os cretenses), e Epimênides, definido como o autor da frase, portanto, um conjunto que a contém, é simultaneamente identificado, pela expressão "de Creta", como membro daquele conjunto. Temos, aqui, uma impossibilidade lógica: um conjunto A que contém um conjunto $B$, que contém um conjunto $C$, que, por sua vez, contém o conjunto A, sem que A, B e C sejam iguais. De um ponto de vista formal, a interpretação lógica dessa asserção exige que tratemos como equivalentes as expressões "Epimênides de Creta" e "cretenses", o que gera um circuito recursivo em que a expressão "Epimênides de Creta" classifica a expressão "todos os cretenses são mentirosos" e é por ela reclassificada, o que exige nova volta ao circuito, e assim por diante, de tal forma que o resultado formal dessa operação será algo como "se sim, então não". No entanto, conforme nota Bateson (1955), a linguagem natural é uma fonte constante de paradoxos desse tipo.

Há três ressalvas para aplicar essa teoria aos fenômenos humanos. Em primeiro lugar, devese reconhecer que a lógica "é um modelo medíocre de causa e efeito" (Bateson, 1986, pp. 66-68), ou seja, as regras que regem o silogismo, com sua estrutura "se... então...", não podem ser aplicadas a ligações do tipo causa-efeito, que também possuem tal estrutura e devem referir-se a eventos que se sucedem no tempo. Skinner (1989, p. 94), por exemplo, com seu lendário rigor epistemológico, reconheceu esse fato ao afirmar que a "unidade preditiva de uma ciência do comportamento não é uma resposta, mas, sim, uma classe de respostas". No caso do rato que ganha uma pelota de comida a cada vez que aperta uma barra,, e, em conseqüência, "aprende a apertar a barra", para que possamos evitar a afirmação falaciosa de que "o rato apertou a barra porque recebeu 
comida", ou seja, o efeito precedendo a causa, precisamos definir o reforço [recebe comida] e o comportamento [aperta a barra] como classes de eventos. Assim, podemos dizer que o rato aprende a seqüência [apertar a barra] $\rightarrow$ [receber comida], ou seja, aprende uma classe de eventos e não uma resposta ' $R$ '. Para adequar-se aos fatos e respeitar a regra básica da causa e efeito, foi necessária a Skinner uma mudança de nível lógico na descrição, de evento para classe de eventos.

Além disso, quando tratamos de seres humanos, é preciso incorporar ao objeto do estudo a linguagem natural, fonte de paradoxos, como já dito, e o mundo interno ao homem, outra fonte de paradoxos, abrindo campo para explicar uma enorme gama de ações e reações que envolvem vários outros tipos de relações causais, inclusive a intencionalidade, que remete ao problema do propósito ou causa final, conhecido como problema teleológico. Nesse caso, no entanto, quando examinamos as soluções científicas consistentes para o problema teleológico, ${ }^{4}$ vemos que esse problema só pode ser resolvido reconhecendo a existência de uma "hierarquia de tipos lógicos inerente aos fenômenos" (Bateson, 1986, p. 123), ou seja, justamente cumprindo as exigências de Whitehead e Russel.

Finalmente, a teoria dos tipos lógicos não tem como objeto os eventos, mas as descrições que deles fazemos, ou seja, nossas teorias e seus cortes epistemológicos. Assim, embora possa não ser um bom instrumento para resolver problemas de causalidade no terreno dos fenômenos humanos, ela seguramente é um bom critério de aferição de discursos científicos que se pretendam rigorosos, tanto porque, nesses discursos a presença de paradoxos é claramente indesejável quanto porque, no caso dos fenômenos humanos, os paradoxos parecem ser inevitáveis. Em outro lugar, afirmei que "a teoria dos tipos lógicos é uma tautologia que pode ser utilizada como critério de avaliação de um corte epistemológico, avaliando as qualidades das descrições e explicações que tal corte possa gerar" (Balieiro, 2002). No caso do psicodiagnóstico e da psicoterapia, sustento que as condições concretas dessas práticas podem ser iluminadas pelo uso da teoria dos tipos lógicos, permitindo não apenas atingir melhor entendimento dessas condições e, conseqüentemente, dos cortes epistemológicos nelas implicados, mas também assentar bases mais consistentes para o próprio debate que as constitui enquanto empreendimento coletivo.

\section{A dimensão pública}

O psicodiagnóstico e a psicoterapia, como práticas de um serviço socialmente regulamentado, ou seja, em sua dimensão pública, articulam-se com instituições e organizações que se situam "fora" do conjunto delimitado pelo terapeuta e pelo paciente na sociedade à qual pertencem. Essa articulação começa pela pré-definição institucionalizada dos papéis de cada um dos sujeitos que se engajam na relação. Esses papéis, complementares entre si, definem uma assimetria hierarquizada bidirecional em que, por um lado, um (o diagnosticador/psicoterapeuta) detém o saber especializado, "científico", e o outro (o diagnosticado/paciente) é objeto/beneficiário desse saber, e, pelo lado oposto, o outro (o cliente/consumidor) compra/recebe o serviço e o um (o terapeuta/prestador de serviço) vende/ presta esse serviço.

Temos então, nessa dimensão, o processo representado como a prestação de um serviço que consiste na aplicação de um certo saber no diagnóstico e tratamento. O paradigma de referência, aqui, é a forma como a sociedade organiza e legitima a prática terapêutica médica, que lida com tratamentos que podem, potencialmente, causar grandes danos ao prescrever drogas que podem ser tóxicas.
4 Penso que essas soluções só podem ser propostas dentro do quadro epistemológico da cibernética, com seus vários modelos de autoorganização. A teoria dos tipos lógicos é central à cibernética $e$ surge em todos os modelos consistentes por ela propostos.

5 Estamos, aqui, analisando a situação de um ponto de vista abstrato. Na prática, $o$ eixo que atribui poderao diagnos ticad ar psicoterapeuta tem sido his toricamente prevalente, embora, à medida que se modernizam as relaçoes Brasil, inclusive no Brasil, o segundo eixo comece a ganhar mais $v i s i b i l i d a d e$, contrabalançando, mesmo que ainda de forma incipiente, a situação. No caso dos serviços públicos de saúde, a equação fica ainda mais complicada, já que a "compra" é indireta, mais dificil de ser utilizada como ser utilizada como cora contrabalançar esse poder. Como o assunto é muito complexo $e$ colateral ao tema deste ensaio, é preferível abstrair essa questão. Acredito, porem, que ela não possa ser deixada de lado. 
Assim, para garantir a segurança da prática, o sistema começa com pesquisadores que apresentam estudos em que certas drogas são descritas como eficientes para certas doenças. Outros pesquisadores, então, aplicam, sob condições controladas, tais drogas a tais doenças, descrevendo os resultados. São, então, elaboradas tabelas de correspondência entre "entidades-doença" e "entidadestratamento". A função desses estudos é o aperfeiçoamento progressivo das terapias, com o aumento da eficiência e a diminuição dos custos, não apenas os financeiros mas também os orgânicos, na forma de efeitos colaterais, e os sociais, representados pela incapacitação causada pelas doenças. Há casos, porém, em que existem tratamentos alternativos para a mesma doença. Elaboramse, então, tabelas estatísticas que prescrevem que, para os mesmos custos, se o tratamento A funciona em $X \%$ dos casos, o tratamento $B$ em $Y \%$ dos casos, e $\{X>Y\}, X$ seja a primeira escolha do médico, não porque $X$ seja intrinsecamente superior a $Y$, mas porque a probabilidade de acertar na escolha é maior. Na maioria das vezes, no entanto, em um caso particular, é difícil definir um indicador prognóstico que diga que $X$ vai funcionar naquele caso específico. Assim, é comum, por exemplo, que o plano de tratamento seja modificado se a primeira escolha $(X)$ não funciona.

No caso do psicodiagnóstico e da psicoterapia, as coisas são complicadas por dois fatores: em primeiro lugar, porque os custos (e perigos!) da psicoterapia ${ }^{6}$ não podem ser mensurados da mesma maneira por que se mensuram os custos da terapia médica; em segundo lugar, porque as especificidades da prática psicoterapêutica trazem para primeiro plano a relação terapeuta-paciente, com a forte exigência da consideração da pessoa do paciente, com suas idiossincrasias. Essa exigência é, talvez, a principal fonte de tensão na discussão sobre a necessidade ou conveniência do psicodiagnóstico em psicoterapia a que nos referimos anteriormente. ${ }^{7}$ Não se pode, entretanto, negar a exigência de algum tipo de "validação" para a prática psicoterápica, o que é, inclusive, exigência do nosso Código de Ética, e vem sendo demonstrado pelas várias discussões sobre modalidades práticas aceitas ou não pelo Conselho Federal e pelos Conselhos Regionais. ${ }^{8}$ Assim, ainda é necessário observar, embora com nuances, o paradigma "teoriapesquisa-validação-prática", e, embora no Brasil essa discussão ainda esteja engatinhando, já começa a ocorrer.

Surge um primeiro plano de fratura: o sujeito, transformado em "objeto de diagnóstico e intervenção", será "encaixado" em uma estrutura pré-construída, preexistente a ele, escolhida pelo diagnosticador entre um grupo delas, disponíveis (supostamente) no estoque de saber que (supõe-se) possui. Essas estruturas de encaixe, embora evidentemente relacionadas umas com as outras, são construídas em obediência a critérios científicos, externos, portanto, tanto à relação terapêutica quanto ao próprio sujeito examinado. Além disso, esses critérios dizem respeito à satisfação de implicações definidas num nível em que esse saber é produzido e sua aplicação desenvolvida, ou seja, no debate teórico sobre doença e tratamento. Em outras palavras, o sujeito é fragmentado em relação aos objetivos e critérios do examinador, definidos em uma instância diferente daquela na qual esses objetivos e critérios serão aplicados. Examinemos mais de perto essa fragmentação.

Um diagnóstico define, no mínimo, quatro classes de implicações que, embora evidentemente interligadas, são distintas: (a) a implicação teórica, explicativa ou doutrinária - "o que é uma doença?", "o que é patológico e o que é normal?", "o que aquela doença nos diz sobre o funcionamento do organismo?"; (b) a implicação funcional, descritiva ou dinâmica - "o que é este 
problema em particular?", "como funciona?", "qual a dinâmica de estados que o caracteriza?"; (c) a implicação nosológica, classificatória ou epidemiológica - "que tipo de doença é aquela?", "qual seu grau de incidência em uma população dada?", "quais suas causas coletivas e como combatê-las"?, e (d) a implicação prognóstica, prescritiva ou normativa ${ }^{9}$ - "qual a terapêutica indicada"? "qual a alternativa à terapêutica indicada, quando esta não funciona?", "como se desenvolve o quadro?", "como o quadro responde ao tratamento?", "quais as chances de cura"?

As duas primeiras implicações - teórica e funcional - remetem o psicodiagnóstico e a psicoterapia a um corpo de conhecimentos que resulta da atividade científica. Dentre as características dessa atividade, aquela que talvez seja a mais bem assentada é sua qualidade de obra em progresso, ou seja: as respostas oferecidas são sempre hipóteses, ou respostas provisórias, a serem aperfeiçoadas constantemente através da crítica e reexame detalhado de cada uma e de seu cotejo com os fatos empíricos. Outro aspecto, cada vez mais acentuado na medida em que as respostas provisórias se acumulam, é o seu caráter coletivo, configurado tanto no fato de que nela vem intervindo um número cada vez maior de atores quanto no fato de que o critério para a aceitação de uma determinada hipótese tem sido, geralmente, a amplitude do apoio que ela recebe do conjunto de atores envolvidos, a "comunidade científica". Seu caráter provisório e coletivo, no entanto, não pode olvidar um terceiro aspecto, muito nítido nas ciências do homem e que lhe é mesmo constitutivo: a ciência é uma atividade conflituosa e polifônica, pois, por um lado, o progressivo aperfeiçoamento das hipóteses surge justamente do conflito produzido pelas vozes discordantes daqueles atores, veiculando e representando teorias e doutrinas opostas e, muitas vezes, incompatíveis, e, por outro lado, quando seu objeto de estudo é o homem, as várias disciplinas, bem como suas teorias e doutrinas, tendem a abordá-lo de pontos de vista diversos, e, assim, dividemno em "componentes" (biológicos, psíquicos, sociais, culturais, etc.) mais ou menos relacionados ou integrados. ${ }^{10}$

Assim, o psicodiagnóstico e a psicoterapia se apóiam num corpo de conhecimentos produzido, gerido e reformulado coletivamente, e definitivamente não estável nem homogêneo, mas, pelo contrário, instável e heterogêneo, tendente à fragmentação e atomização. Como conseqüência dessa instabilidade e heterogeneidade e da tendência à fragmentação e atomização, embora lidemos com organismos totais, a análise e o entendimento (diagnóstico) e a intervenção (terapia) de/em cada um daqueles componentes (biológicos, psíquicos, sociais, culturais, etc.) acaba por mobilizar "saberes" também fragmentados, quando não isolados (Medicina, Psicologia, Sociologia, Antropologia, Lingüística, etc.), dividindo o sujeito examinado em relação a si mesmo, enquanto sujeito mesmo, em dimensões (biopsicossocial, etc.) nem sempre compatíveis, divisão cujos critérios são geralmente de caráter teórico ou doutrinário. Grosseiramente falando, "uma perspectiva biológica acha que tudo vem do corpo", "uma perspectiva psicológica acha que tudo vem da mente", "uma perspectiva sociológica acha que tudo vem da sociedade", etc. Estamos, então, defronte a um primeiro perigo a que esse plano de fratura submete a atividade psicodiagnóstica: a ausência ou a dificuldade de estabelecimento de uma perspectiva teórica unificada sobre o objeto de análise - a pessoa/sujeito - pode conduzir a uma análise instável, reducionista, heterogênea ou fragmentária, que o reduzirá a agrupamentos mais ou menos consistentes de entidades teóricas muitas vezes não relacionadas ou incomensuráveis entre si, como "hipotálamo", "ego", "estímulo", "reforço", "consciência", "motivação", "pulsão", etc.
Assim, o psicodiagnóstico e a psicoterapia se apóiam num corpo de conhecimentos produzido, gerido e reformulado coletivamente, e definitivamente não estóvel nem homogêneo, mas, pelo contrário, instávele heterogêneo, tendente à fragmentação e atomização.
9 Por normativa, estou referindo-me à norma social, coletiva, ligada à regulamentação legal da prática terapêutica. É evidente que reconheço que as outras classes de implicaçoes também imensão normativa, mas, nesta implicação, quero ressaltar o caráter jurídico ou legal da dimensão normativa.

10 Na Psicologia e na psicopatologia, podemos dizer que a diversidade de pontos de vista a partir dos quais são abordados os fenomenos (Medicina, psiquiatria Psicologia psicanálise, Peurologia, etc.) configu neurologia, etc.) configura, mais do que uma polifonia, uma verdadeira cacofonia, uma selva teórica muitas vezes dificil de desemaranhar. 
Tal perigo tem sido enfrentado, na maior parte das vezes, através da escolha, pelo psicoterapeuta, de uma "linha", ou seja, da filiação a uma escola defensora de uma doutrina teórico-técnica que define o conjunto de postulados sobre o que é e como se compõe o sujeito - uma ontologia ou teoria e um conjunto de procedimentos permitidos e proibidos na psicoterapia - uma metodologia ou técnica. Na dimensão científica em que são construídas e avaliadas, essas doutrinas também devem definir o conjunto de problemas que podem ser abordados/ resolvidos dentro de seu escopo. Devemos, no entanto, reconhecer que, mesmo que essa definição de aplicabilidade aconteça, nem sempre é levada em conta na prática psicoterapêutica cotidiana. Ainda assim, a escolha de uma "linha" não apenas tem sido geralmente definida como desejável, mas, muitas vezes, imposta como inevitável, sob pena de o psicoterapeuta ser acusado de "ecletismo", uma acusação considerada grave na esfera científica, embora os psicoterapeutas não ligados à academia não pareçam importarse muito com isso.

É preciso, ainda, considerar que essa estratégia de enfrentamento da fragmentação do cliente através da escolha de doutrina pode tornarse, em si mesma, uma nova fonte de problemas. Em primeiro lugar, porque, pela sua própria natureza epistemológica, as doutrinas geralmente implicam um alto grau de universalização de sua aplicabilidade, com o que se corre o risco de tomar a doutrina (e suas aplicações) como uma panacéia genérica que pode ser aplicada a qualquer problema, e, além disso, como alguns aspectos das doutrinas, e mesmo algumas doutrinas como um todo, não são suficientemente refutáveis para serem testadas empiricamente, adicionase o risco de, quando uma de suas aplicações não funciona, o problema seja atribuído ao cliente e não à doutrina, cuja revisão pode ser ou parecer impossível por conta dessa irrefutabilidade. Um outro tipo de problema é o forte cunho ideológico com que a escolha doutrinária, e o modelo técnico dela decorrente, é, muitas vezes, tratada, implicando discussões que mobilizam outra esfera-política-aumentando a complexidade da escolha. Sem estender-me muito no assunto, acredito que qualquer reflexão sobre escolhas doutrinárias, para enfrentar a complexidade do assunto, precisa ser disciplinada por uma crítica epistemológica rigorosa, como a que tento aqui, e por um forte e explícito compromisso com o cunho coletivo dessa reflexão, caso contrário, ou caímos em uma espécie de regressão infinita, em que a tentativa de solução de um paradoxo acaba por gerar outro paradoxo, indefinidamente, ou caímos em um diálogo de surdos que irá, certamente, bloquear qualquer possibilidade de progresso.

As duas outras implicações - nosológica e prognóstica - remetem o psicodiagnóstico e a psicoterapia à regulamentação e controle social sobre uma prática que cumpre uma importante função na sociedade organizada: o cuidado com a saúde. Essa regulamentação e esse controle, típicos da organização jurídicoinstitucional do Estado moderno, tem como fundamentos duas idéias complementares: por um lado, prover ao cidadão garantias de que o Estado cuidará de seus direitos humanos fundamentais (vida e saúde); por outro lado, garantir a qualidade dos serviços prestados ao cidadão (aqui, com o status de cliente ou consumidor) pelos agentes encarregados daqueles cuidados. A primeira idéia é materializada nos sistemas de saúde coletiva de caráter estatal, como o SUS, por exemplo, e nas agências não estatais aceitas e fiscalizadas pelo Estado. ${ }^{11}$ A segunda é materializada nas diversas regulamentações profissionais, como diploma, registro profissional, títulos, etc., que autorizam e restringem o direito de prestar serviços de saúde às pessoas que possuam a chancela oficial. Tanto para implementar os sistemas de atendimento coletivo à saúde quanto para conceder a chancela oficial, ou a 
garantia de qualidade ao serviço prestado, no entanto, o arcabouço jurídico-institucional lança mão, como gabarito, justamente do conhecimento científico, como pode ser visto, por exemplo, no Art. 01, alínea c) do Código de Ética Profissional do Psicólogo: "São deveres fundamentais do psicólogo: (...) c) Prestar serviços psicológicos em condições de trabalho eficiente, de acordo com os princípios e técnicas reconhecidas pela ciência, pela prática e pela ética profissional" (itálicos acrescentados). E, uma vez que esse reconhecimento, como vimos, está longe de ser homogêneo, estável e unificado, surge outro paradoxo: é preciso garantir a qualidade do serviço, ou seja, sua conformidade a uma certa especificação, mas essa especificação não pode ser completamente garantida.

As formas escolhidas para o enfrentamento desse paradoxo podem ser classificadas em um continuum que, num extremo, consiste em uma completa submissão aos sistemas classificatórios, com a definição de tabelas que relacionam entidades nosológicas ("doenças") que "acometem" o sujeito com entidades terapêuticas ("protocolos de tratamento") a que o sujeito portador da "doença" deve ser "submetido", sob pena de se cometer um "erro médico". No outro extremo, apresentada como uma reação justificável à base epistemológica "positivista" implícita nessa primeira opção, ${ }^{12}$ aparece uma completa recusa de qualquer tipo de diagnóstico, numa espécie de "defesa do irracionalismo" configurada nos mais diversos tipos de "terapias alternativas", aplicáveis a todo e qualquer problema como panacéias mágicas. ${ }^{13}$ Metaforicamente, temos, de um lado, o físico de que fala Saint-Exupéry, que, após fazer um certo número de exames e cálculos, decide qual a "doença", satisfazendo assim a implicação nosológica, e, então, define qual a pílula a ser ministrada para aquela "doença", satisfazendo, assim, a implicação prognóstica. Do outro lado, encontramos não o velho médico do interior, como supõe Saint-Exupéry, mas o charlatão vendedor de um elixir miraculoso, que cura desde unha encravada até espinhela caída.

Surge, aqui, um segundo perigo a que esse plano de fratura submete a atividade psicodiagnóstica: o risco permanente de que, num extremo, seja apagada a integridade funcional da entidade pessoal ("sujeito") do "paciente" (ou seja, a sua "subjetividade") em nome de sua "classificação" em uma tabela de "doenças", ou, no extremo oposto, que sua "subjetividade" seja erigida em barreira, levando a que uma situação claramente solucionável através do uso de algum protocolo pré-definido seja submetida a tratamentos ineficazes. O curioso é que os dois extremos são claras tentativas de encaixar o cliente num "leito de Procusto"; afinal, se encaixá-lo em uma tabela de correspondências "doença/ tratamento" deixa de levar em conta particularidades de sua organização interna que seguramente interferem no tratamento, submetê-lo a um tratamento pré-definido por razões doutrinárias não verificáveis também deixa de levar em conta essas particularidades, ou seja, tanto num quanto noutro caso sua subjetividade é ignorada.

Penso que a compreensão e a superação desses paradoxos exige que reconheçamos o fato de que esses paradoxos são inevitáveis, pois resultam de uma característica que se inscreve na própria tessitura do discurso científico: declarações sobre eventos singulares ou indivíduos identificados implicam um tipo de operação lógica diferente do tipo de operação presente em declarações sobre conjuntos ou classes de eventos ou indivíduos, e essas operações são incomensuráveis entre si, já que, parafraseando Bateson (1986), nenhum discurso rigoroso pode conter declarações de dois tipos lógicos diferentes sem geração de paradoxos. No caso que estamos examinando, é preciso estabelecer claramente que o nível lógico no qual se podem fazer declarações sobre populações não
12 Há muita semelhança entre este meu argumento e a tese defendida por Figueiredo (1991), que me parece justamente reconhecer esse conflito como constitutivo da Psicologia. Embora não possa responsabilizá-lo pelos enganos que eu tenh cometido nesta reflexão. quero deixar claro que foi $\mathrm{em}$ suas idéias que me inspirei.

13 Em sociedades em que a atividade de saúde é fortemente regulada por mecanismos legais genéricos, como os EUA, por exemplo, aparecem nitidamente as duas faces do paradoxo: por um lado, os médicos fazem seguro contra processos por "erro médico" (10 que pressupóe a médico noção de "acerto médico" e evoca a imagem do fisico de Saint-Exupéry), e são $p r o c e s s$ a d o s freqüentemente; por outro lado, proliferam incessantemente os "tratamentos milagrosos", que são vendidos aos montes e rapidamente esquecidos (como a indústria da "dieta revolucionária"). 
é o mesmo nível lógico em que se podem fazer declarações sobre indivíduos. Nas palavras de Bateson (1986, p.49), "existe um profundo abismo entre afirmações sobre um indivíduo identificado e afirmações sobre uma classe de indivíduos", ou seja, no caso da psicoterapia, o discurso sobre a população, embora tenha implicações para o indivíduo (cliente), deve ser pensado como um metadiscurso em relação ao discurso sobre os indivíduos que compõem essa população, e não pode, portanto, ser diretamente aplicado à pessoa do cliente sem sofrer uma alteração de nível lógico. ${ }^{14}$

Além disso, enquanto no plano de fratura até aqui examinado as implicações do psicodiagnóstico agrupam-se em torno de dois eixos - o empreendimento científico e o ordenamento jurídico - , no nível em que seus discursos se constituem e articulam, o agrupamento dessas implicações obedece a um outro critério, de caráter epistemológico, gerando dois outros eixos: o classificatório e o terapêutico. O discurso classificatório - no nosso caso, as implicações (a) teórica, explicativa ou doutrinária e (c) nosológica, classificatória ou epidemiológica - tem como objeto a população como um todo, nível em que o sujeito é uma entidade abstrata, não realizada em nenhum indivíduo específico, enquanto o discurso terapêutico - no nosso caso, as implicações (b) funcional, descritiva ou dinâmica, e (d) prognóstica, prescritiva ou normativa - tem como objeto sujeitos específicos, sofrendo de problemas específicos e precisando de um tratamento específico. Reconhecer esses outros dois eixos permite perceber que os paradoxos gerados nos sistemas classificatórios e na polifonia teórica são constitutivos da própria Psicologia enquanto ciência/técnica, e a crítica que permite perceber sua presença não os torna menos reais nem os dilui. O que me parece assentado é que tanto o empreendimento científico quanto o ordenamento jurídico precisam reconhecer e levar em conta tais paradoxos.

\section{A dimensão privada}

Em sua dimensão privada, o psicodiagnóstico e a psicoterapia decorrem do estabelecimento de uma relação de certo tipo entre o terapeuta e o cliente: "a psicoterapia é uma forma especial de relacionamento humano e a qualidade de tal relacionamento parece ser um importante fator de influência sobre as vidas dos participantes" (Mahoney, 1998, p. 316). Já que, como vimos, a pré-definição institucional dessa relação define papéis que se articulam em uma assimetria hierarquizada bidimensional, examinemos as implicações dessa assimetria para o estabelecimento da relação em si.

O primeiro tipo de paradoxo que pode surgir dessa assimetria é a tensão entre o terapeuta que sabe e o terapeuta que presta um serviço, que dissecamos quando da discussão da dimensão pública. Muitas vezes, o próprio cliente expressa os pólos dessa tensão quando, por exemplo, concede ao terapeuta o poder do "saber profissional" ("mas o que é que eu tenho, doutor?; mas o que é que eu devo fazer então?"), ou reivindica esclarecimentos "devidos" ("eu tenho o direito de saber quanto vai durar e quanto vai custar!"). As respostas dadas pelos terapeutas a tais tipos de perguntas revelam suas estratégias para manejar essa tensão, e também aqui encontramos um continuum em que, numa das pontas, temos o terapeuta que se recusa a responder à pergunta ou interpreta a pergunta em termos do que ela revela sobre aspectos internos do cliente, aparentemente recusando a hierarquização, mas mantendo-a em outro nível, já que recusa ao cliente qualquer possibilidade de determinar a forma de prosseguimento da relação, e, na outra ponta, o terapeuta que responde à pergunta sem questionar a hierarquia nela implícita, contribuindo de bom grado, mesmo que involuntariamente, para sua manutenção. Vale ainda dizer que, enquanto a primeira direção (o profissional como sábio) é conhecida, e 
manejável, dentro dos modelos de trabalho com os quais nós, clínicos, estamos acostumados, a segunda (o cliente como consumidor) ainda precisa ser melhor discutida e compreendida, inclusive porque - acredito - tende a aumentar de freqüência, acompanhando o crescimento da consciência dos direitos do consumidor. Os paradoxos, aqui, são conseqüência direta da existência de duas direções de exercício de poder e dos dois modos de discurso relacionados com cada uma.

Uma segunda nova fonte de paradoxos, mais bem estudada e compreendida, é que a exigência de profissionalização da relação contrasta com sua necessária pessoalidade. Aqui, temos que compatibilizar dois níveis de análise da relação: o nível em que a relação se articula com sua externalidade, enquanto atividade profissional, e o nível em que as pessoas envolvidas estabelecem a relação. A materialização desses paradoxos se dá no conjunto de condições - comumente designado como 'contrato' ou 'setting' - que organiza a relação. Nesse caso, temos, por um lado (a), as condições de restrição a que os sujeitos - terapeuta e paciente - estão submetidos, ou seja, as condições externas que o contrato deve satisfazer; e, por outro lado, (b) as condições de facilitação para que a relação tenha uma certa qualidade que lhe permita influenciar as vidas dos participantes na direção pretendida pelo cliente. Estas últimas têm sido consistentemente examinadas pela pesquisa sobre a psicoterapia, o que nos exime de examiná-las mais a fundo. ${ }^{15}$

Entre as condições de restrição, o paradoxo parece surgir da tensão entre, por um lado, as regras de relacionamento pré-definidas e "herdadas" da dimensão pública, já examinadas, e, por outro lado, os motivos do cliente para buscar esse serviço, que podem ser conceitualizados, genericamente, como uma demanda por mudança (Mahoney, 1998).
A demanda por mudança pode, por sua vez, ser organizada em duas classes gerais: (a) a busca por algum tipo de "autodesenvolvimento", cujo foco central é o autoconhecimento, remetendo ao ethos, e (b) a busca por algum tipo de "cura", cujo foco central é o alívio da dor, remetendo ao pathos. É claro que essas duas classes estão imbricadas de diversas formas, sendo, algumas vezes, difícil discerni-las ou distingui-las sem incorrer em artificialismos, assim como a fronteira entre ethos e pathos é bastante nebulosa. Ainda assim, é evidente que existem e que suas implicações são bastante diferentes, tanto no que se refere à questão da relação entre terapia e diagnóstico quanto no que se refere às condições de regulamentação que citamos quando da discussão da dimensão pública.

A busca por "autodesenvolvimento" pode originar-se da insatisfação com as condições da própria vida, mas, mais geralmente, surge da busca de esclarecimento e compreensão para questões existenciais que, mesmo gerando angústia e sofrimento, não são resultado de disfunção ou doença, mas do processo natural de evolução e desenvolvimento da pessoa e das exigências concretas de sua vida. O status e o papel do profissional psi (que, neste caso, poderíamos chamar, talvez mais propriamente, de analista ou conselheiro) são bem pouco restringidos pelas condições externas ao contrato. É preciso render-se à evidência de que esse tipo de demanda não está diretamente relacionada com o que vimos chamando de psicodiagnóstico e, mesmo que certamente envolva alguma forma de avaliação psicológica, não é redutível às análises que vimos fazendo, e, possivelmente, nem mesmo às normas legais atualmente existentes, pois, uma vez que remete ao ethos e não ao pathos, não pode ser regulamentada num sentido estrito como um "serviço de saúde". Talvez deva ser pensado como um serviço "pedagógico", ou "de aconselhamento". Aqui, o paradoxo surge quando tentamos reduzir a demanda do cliente
15 Para uma visão bem atual dessas condições, ver Cordiolli (1998), especialmente a parte $1, e$ também Mahoney (1998) especialmente os capítulos $1,10,12$ e 13 
ao pathos, o que pode ser caricaturado por declarações do tipo "todo mundo é neurótico, em algum grau". É evidente que essa declaração, além de ser simplesmente uma petição de princípio de fundo exclusivamente doutrinário, acaba por apagar qualquer possibilidade de que se estude a fundo o que é ser "neurótico", abrindo caminho para a declaração oposta "então o normal é ser neurótico", e a própria categoria de pathos perde seu sentido.

A demanda por "cura", entretanto, implica a presença de algum tipo de problema que possa ser claramente classificado como disfunção ou doença, e assinalada em algum modelo de pathos. Esses problemas sempre apresentam dois aspectos, um subjetivo e outro objetivo, que denominarei livremente sofrimento e patologia. No seu aspecto sofrimento, o problema remete ao "mundo interno" do cliente, e somente pode ser compreendido dentro do enquadre (Bateson, 1955) formado pelas premissas que organizam o modo pelo qual o cliente percebe, vivencia e se relaciona com o mundo em que está inserido. Em outras palavras, o sofrimento e sua conseqüente cessação só fazem sentido "da perspectiva do cliente". Em seu aspecto patologia, por outro lado, essa demanda só faz sentido, como vimos, em um contexto pré-organizado articulado com e na dimensão pública. Deparamo-nos, novamente, com a necessidade de compatibilizar dois discursos de níveis lógicos diferentes: o discurso sobre o indivíduo e o discurso sobre a população, emergindo um outro plano de fratura: a compreensão do sofrimento e da patologia exige reconhecer que, embora caminhem muitas vezes juntos, não são uma só entidade e, muitas vezes, são incomensuráveis.

Detenhamo-nos primeiro no problema da compreensão da patologia. A grande importância dada pelos profissionais de saúde mental à tradição de estudos de caso testemunha o desafio apresentado pela diversidade de manifestações do pathos nas diferentes pessoas. Os próprios sistemas de critérios diagnósticos coletivos já mencionados (CID e DSM) apresentam listas de sintomas que permitem, às vezes, classificar como uma mesma patologia manifestações completamente diferentes. Além disso, grande parte dos sinais interpretáveis na semiologia da saúde mental são relatos e manifestações verbais dos próprios pacientes, inevitavelmente vertidos na sua própria e idiossincrásica linguagem. Finalmente, a dificuldade de uma definição positiva incontroversa de saúde ou normalidade (Canguilhem, 2002) faz com que o terapeuta tenha que transitar entre definições muitas vezes incomensuráveis ou mesmo incompatíveis. Dalgalarrondo, por exemplo, (2000, pp. 25-27) lista nove linhas possíveis na definição do conceito de "normalidade" ou "saúde" em psicopatologia. Representando um ponto de vista oposto, Unger (1982, 1998), por exemplo, acusa a psiquiatria (e a psicopatologia) de terem progressivamente abandonado esse problema, e argumenta pela necessidade de uma teoria normativa da personalidade, propondo, como centro dessa reflexão, o fenômeno da paixão, que seria "nosso desejo de sermos aceitos uns pelos outros e de nos tornarmos, por meio dessa aceitação, mais livres para nos reinventarmos" (p.7).

Esse debate tem crescido em amplitude e temperatura, como dissemos anteriormente, mas cabe assinalar que as formas encontradas na prática profissional dos psicoterapeutas para responder às questões aqui colocadas também parecem variar em um continuum em que, de um lado, temos novamente aquela aplicação mecânica das 'tabelas de correspondências doença-tratamento' a que já nos referimos anteriormente, e, de outro lado, uma teimosa recusa a pensar o cliente em termos de pathos. Acredito que a prática tenha apontado uma convergência, mesmo 
que ainda distante, em direção a algum ponto intermediário desse continuum. Mesmo nas áreas mais facilmente delimitáveis da psicopatologia, como o tratamento das fobias, temos visto um movimento progressivo na direção de trabalhar sempre com um "diagnóstico provisório", ou seja, um diagnóstico que progride junto com o tratamento, num contínuo diálogo entre a prática clínica e a teoria psicopatológica. ${ }^{16}$ Ainda assim, essa é uma importante fonte de paradoxos, já dissecada quando falamos da dimensão pública.

Quanto ao problema de compatibilizar o discurso científico adequado ao pathos com o discurso prático adequado à especificidade da relação terapêutica concreta, podemos dizer que, de modo geral, os psicoterapeutas bem sucedidos parecem adotar quase universalmente uma espécie de solução de compromisso que, normalmente, apóia-se em declarações de princípio do tipo "terapia é, ao mesmo tempo, uma ciência e uma arte", buscando alicerçar sua prática no arsenal científico, mas dando a ela um "toque pessoal" que, na prática, diferencia o bom do mau terapeuta. Como terapeuta praticante há 16 anos, posso afirmar que a prática terapêutica nunca é tão padronizada e mecânica quando pode fazer supor o discurso científico, trazendo, como disse antes, boa dose de "arte". Penso que o silêncio no debate sobre o aspecto "artístico" da prática terapêutica está, em certa medida, relacionado com a dificuldade de padronizar esse aspecto e, conseqüentemente, de darIhe "legitimidade" social. Entretanto, essa postura gera o permanente risco de que sejam legitimadas práticas que misturam conhecimentos cientificamente validados com bobagens grosseiras como a astrologia ou coisas do tipo.
Quando, porém, nos deparamos com o problema do sofrimento, o terreno torna-se muito mais instável e pantanoso, pois sua compreensão, e, conseqüentemente, qualquer tipo de psicodiagnóstico, exige uma perspectiva unificadora do paciente que o torne um sujeito, já que nunca se consegue eludir completamente (talvez nem mesmo com as malfadadas lobotomias) o fato de que tanto o "terapeuta" quanto o "paciente" são pessoas completas autonomamente organizadas em que o "self", como quer que se o defina, ocupa um papel central, e o objetivo de qualquer tratamento é justamente a manutenção, a preservação, ou a recuperação, ainda que parcial, dessa autonomia organizacional, às vezes chamada de "manutenção da vida e da saúde".

Simplificando: por um lado, uma compreensão produtiva, em termos terapêuticos, do sofrimento, exige a famosa empatia de Carl Rogers (Rogers, 1972), ou seja, é preciso que o terapeuta "consiga ver com os olhos do cliente", isto é, em certa medida, "sair de si mesmo"; por outro lado, é impossível evitar o viés do terapeuta, também um sujeito com suas próprias idiossincrasias. Além disso, se, como vimos sustentando, a qualidade da relação é central para seu efeito terapêutico, o terapeuta, inevitavelmente, vem a ser parte de seu próprio instrumental de trabalho. Num nível mais abstrato, podemos dizer que uma perspectiva unificadora somente pode surgir na presença de algum tipo de teoria antropológica, uma teoria da pessoa (ou uma "visão de homem" como se costuma denominar esse tipo de teoria em nossos cursos de graduação). Emerge, então, um outro paradoxo: é preciso compatibilizar o "olhar de fora" com o "olhar de dentro". É evidente que psicoterapeuta, nesses casos,
16 Veja-se, por exemplo, Abreu (2001). 
vai, muitas vezes, ser confrontado com decisões profundamente pessoais, o que, de passagem, sustenta a exigência de que o terapeuta "cuide de si mesmo", como diz Mahoney (1998, p. 330).

\section{Conclusão}

O assunto deste ensaio é, no mínimo, de duas ordens de complexidade, já que é um fenômeno complexo resultante do entrecruzamento de dois outros fenômenos complexos. Considero minha abordagem apenas uma aproximação do problema, cujo mérito, se existe, consiste em propor um critério - a teoria dos tipos lógicos - que permita aumentar o rigor de nosso exame sobre as fontes de paradoxos constitutivas do fenômeno. Ainda assim, quero arriscar algumas conclusões do exame que empreendi.

Em primeiro lugar, penso que devemos recordar que, como já mostrara Rogers e vem sendo seguidamente reiterado por pesquisadores contemporâneos, como Mahoney, os três melhores prognosticadores do êxito da terapia são: a personalidade (e a motivação) do cliente, a personalidade (e a disposição) do terapeuta e a relação que se estabelece entre essas pessoas, enquanto a doutrina teórica e o modelo de tratamento professados pelo terapeuta são bem menos importantes. Ainda assim, é justamente no diálogo entre as várias doutrinas que podemos ter a esperança de gerar algum progresso que nos leve para além de platitudes do gênero "terapia é ciência e arte".

Em segundo lugar, penso que devemos levar em conta que, sempre que praticamos a psicoterapia, estamos pessoalmente engajados em um tal nível de intensidade que possivelmente personalizamos, além da conta, a discussão sobre nossas práticas. Aqui cabe a cobrança de um pouco mais de generosidade na crítica, que permita que nossas posições pessoais sejam acolhidas pelo menos com o mesmo cuidado com que acolhemos as queixas de nossos clientes.

Em terceiro lugar, penso que a junção dessa intensa pessoalidade com a prática clínica individual solitária que predomina entre nós, com suas inevitáveis idiossincrasias, acaba sendo a fonte de um viés que nos deixa aos psicoterapeutas - muito refratários aos empreendimentos coletivos, e, como conseqüência, as discussões sobre nossas práticas, quando ocorrem, ou surgem na impessoalidade dos periódicos - pouco lidos, diga-se de passagem -, ou surgem nos corredores de congressos, na provisoriedade de rápidos contatos face a face, ou surgem nas supervisões que, se não continuam parecendo a prática clínica solitária, são deformadas pelo medo natural que todos temos de sermos julgados como pessoas. Aqui, cabe a cobrança de um pouco mais de pretensão para que corramos o risco de compartilhar nossas convicções, paradoxalmente temperada com um pouco mais de humildade para que nos exponhamos ao escrutínio dos colegas sem a pretensão de estarmos sempre certos.

Finalmente, acredito que possa haver, nas discussões sobre a prática, uma certa radicalização ideológica que pode desaguar em muitos modos autoritários de crítica, mesmo que insidiosamente e contrariamente a nossos objetivos explícitos. Não defendo a pureza ideológica do debate nem nenhum tipo de assepsia positivista, mas, sim, um engajamento que parta do princípio de que o meu interlocutor - o outro - tem intenções pelo menos tão boas e honestas quanto as minhas. 


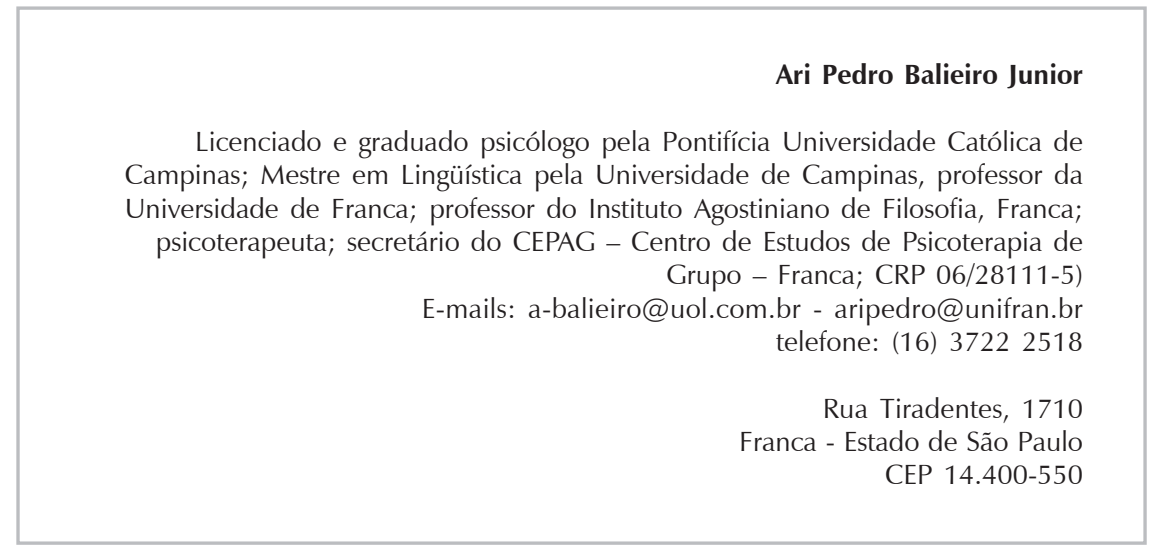

Recebido 20/07/04 Reformulado 22/05/05 Aprovado 15/07/05

ABREU, C. N. Psicoterapia Construtivista: o Novo Paradigma dos Modelos Cognitivistas. In Rangé (2001).

APA - AMERICAN PSYCHIATRIC ASSOCIATION. Manual Diagnóstico e Estatístico de Transtornos Mentais. Porto Alegre: Artes Médicas, [Ó1994] 1995.

BALIEIRO JUNIOR, A. P. "Sujeito, Discurso e Representação Lógica”. In Linguagem em (Dis)curso. Tubarão, v. 2, n. 2, pp. 9-28.

BATESON, G. Una Teoría del Juego y de la Fantasia. In Baterson, [Ó1955] 1972.

Passos Hacia una Ecología de la Mente - una Aproximación Revolucionária a la Autocomprehensión del Hombre. Buenos Aires: Planeta-Carlos Lohlé, [Ó1972] 1992.

. Mente e Natureza: a Unidade Necessária. Rio de Janeiro: Francisco Alves, [Ó1979] 1986.

BECK, A. T. \& ALFORD, B. A. O Poder Integrador da Terapia Cognitiva. Porto Alegre: Artmed, [Ó1987] 2000.

CANGUILHEM, G. O Normal e o Patológico. Rio de Janeiro: Forense Universitária, [Ó1966] 2002.

CFP - Conselho Federal de Psicologia. Código de Ética Profissional dos Psicólogos. Disponível em versão digital na World Wide Web. URL: http://www.pol.org.br/arquivos_pdf/ código_de_ética_formatado.pdf, 1996.

CORDIOLLI, A. V. (org). Psicoterapias: Abordagens Atuais. $2^{\text {a }}$ ed. Porto Alegre: Artes Médicas, 1998.

CUNHA, J. A. e cols. Psicodiagnóstico. - V. Porto Alegre: Artes Médicas Sul, 2000a.

CUNHA, J. A. Prefácio. In Cunha, J. A. e cols. 2000a e 2000b. . Estratégias de Avaliação: Perspectivas em Psicologia Clínica. In Cunha, J. A. e cols. 2000a e 2000c.

. Fundamentos do Psicodiagnóstico. In Cunha, J. A. e cols. 2000a e 2000d.

DAlgalarrondo, P. Psicopatologia e Semiologia dos Transtornos Mentais. Porto Alegre: Artes Médicas, 2000.
FIGUeIREDO, L. C. Matrizes do Pensamento Psicológico. 4aa ed. Petrópolis: Vozes, [1989] 1991.

HETEM, L. A. \& GRAEFF, F. G. eds. Ansiedade e Transtornos de Ansiedade. Rio de Janeiro: Editora Científica Nacional, 1997.

LOPES, M. S. Classificação dos Estados de Ansiedade. In Hetem, L. A. \& Graeff, F. G. eds. Ansiedade e Transtornos de Ansiedade. Rio de Janeiro: Editora Científica Nacional, 1997.

MAHONEY, M. J. Processos Humanos de Mudança : as Bases Científicas da Psicoterapia. Porto Alegre: Artmed, [Ó1991] 1998. OMS - Organização Mundial da Saúde. Classificação de Transtornos Mentais e de Comportamento da CID-10. Descrições Clínicas e Diretrizes. Porto Alegre: Artes Médicas, [Ó1992] 1993.

RANGÉ, B. (org.) Psicoterapias Cognitivo-comportamentais. Porto Alegre: Artmed, 2001.

SAINT-EXUPÉRY, A. Escritos de Guerra: 1939-1944. Rio de Janeiro: Nova Fronteira, [Ó1982] 1984.

SKINNER, B. F. Ciência e Comportamento Humano. São Paulo, Martins Fontes, [1953] 1989.

SILVA JUNIOR, N. e FERRAZ, F. C. O Psicodiagnóstico entre as Incompatibilidades de seus Instrumentos e as Promessas de uma Metodologia Psicopatológica. Psicol. USP, vol.12, no.1, 2001, pp.179202.

WATZLAWICK, P.; WEAKLAND, J. H. \& FISCH, R. Mudança Princípios de Formação e Resolução de Problemas. São Paulo: Cultrix, [Ó 1973] 1977.

WHITEHEAD, A. N. \& RUSSEL, B. Principia Mathematica. Londres: Cambridge University Press, 1910.

ROGERS, C. R. Tornar-se Pessoa. São Paulo: Martins Fontes. [Ó $1961] 1972$.

UNGER, R. M. Um Programa para a Psiquiatria na Virada do Século XX. In Unger, [Ó 1984] 1982.

Paixão - um Ensaio sobre a Personalidade. São Paulo: Boitempo, [Ó 1984] 